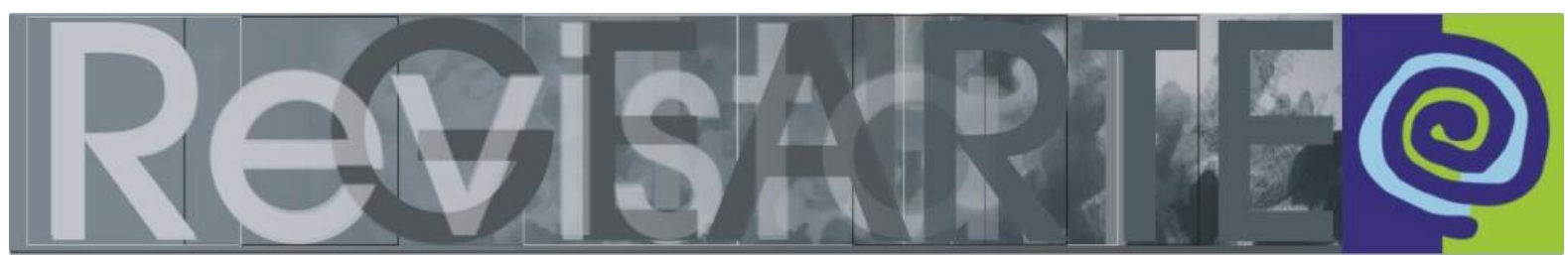

ISSN 2357-9854

\title{
Políticas públicas de formação docente em artes: perspectivas em duas realidades, Brasil e Argentina
}

\author{
Maria Cristina da Rosa Fonseca da Silva (Universidade do Estado de Santa Catarina \\ - UDESC, Florianópolis/ SC, Brasil)
}

\author{
Federico Ignacio Buján (Instituto Universitario Nacional del Arte —IUNA, Buenos \\ Aires, Argentina)
}

RESUMO - Políticas públicas de formação docente em artes: perspectivas em duas realidades, Brasil e Argentina - Este artigo aborda pesquisas do Observatório da Formação de Professores de Artes Visuais (que agrega seis Instituições de Ensino Superior do Brasil e duas da Argentina) que resultaram em um mapeamento das principais legislações que regulamentam a formação inicial dos professores de Artes Visuais. Analisa documentos oficiais e políticas públicas dos dois países e evidencia a existência de tensões nos dois sistemas de educação. Observa diferenças e similaridades entre os dois contextos, oferecendo subsídios para repensar a própria formulação de políticas públicas para os cursos de formação de professores de Artes Visuais.

PALAVRAS-CHAVE

Legislação. Artes visuais. Licenciaturas. Formação docente. Observatório.

RESUMEN - Políticas públicas de formación de profesores de Educación Artística: perspectivas en dos realidades, Brasil y Argentina - En este artículo se discute las investigaciones del "Observatório da Formação de Professores de Artes Visuais" (que comprende seis Instituciones de Educación Superior de Brasil y dos de Argentina), que han resultado en un mapeo de las principales legislaciones que reglan la formación inicial de los profesores de Educación Artística. Analiza documentos oficiales y políticas públicas de los países y muestra la existencia de tensiones en los dos sistemas educativos. Además, apunta diferencias y similitudes entre los dos contextos, ofreciendo subsidios para reconsiderar la formulación de políticas públicas para los cursos de formación de profesores de Educación Artística.

\section{PALAVRAS CLAVE}

Legislaciones. Artes Visuales. Graduación. Formación docente. Observatorio.

O presente artigo é parte dos estudos desenvolvidos junto ao Observatório da Formação de Professores de Artes Visuais que, nesta etapa, analisa os documentos legais que desenham os modelos de formação propostos pelos governos brasileiro e argentino. No Brasil, os cursos de licenciatura devem seguir a Lei de Diretrizes e Bases da Educação Nacional (LDB), bem como as diretrizes para a formação de professores de artes visuais (DCNAV) e as diretrizes para a formação de professores para a educação básica (DCFPEB). Neste sentido, produziu-se, com este artigo, uma 
análise considerando os aspectos qualitativos que colaboram para repensar as políticas indutoras de formação.

Acredita-se que os documentos evidenciam o modelo proposto pelos gestores que transformam seus ideários em políticas públicas de formação de professores. No lado argentino, focou-se na Lei de Educação Nacional (LEN), na Lei de Educação Superior (LES) e em algumas resoluções e normativas específicas do Conselho Federal de Educação (CFE) e do Instituto Nacional de Formação Docente (INFD). Como resultado, no lado brasileiro, observou-se a implementação de slogans educacionais que criam tendências sazonais de formação, falta de projetos de Estado que ultrapassem os mandatos governamentais, bem como uma visão polissêmica do ideário pedagógico veiculado nos documentos legais. No lado argentino, foi necessário considerar a conformação do sistema de ensino superior em dois subsistemas e o modo em que as legislações e regulações operam em cada um deles, sendo possível identificar algumas superposições entre as normativas correspondentes a esses diferentes níveis de regulação, produzindo-se tensões entre as distintas instâncias reguladoras. A perspectiva de políticas públicas para a educação na América Latina vem sendo desenvolvida desde a década de 1990 com a produção de uma formação aligeirada e funcional buscando encobrir a condição de exploração docente. Neste artigo, ocupa-se em examinar como essas problemáticas operam na área da formação de professores de artes nos contextos argentino e brasileiro, produzindo aportes que dão conta dos modos em que esses níveis se articulam e dos aspectos que concentram as principais tensões na área circunscrita.

\section{INDICAÇÕES INICIAIS DO PROJETO OBSERVATÓRIO}

Este trabalho se originou a partir de uma série de interrogantes que orientam algumas das linhas de estudo do projeto de pesquisa bilateral entre Brasil e Argentina, como o "Observatório da Formação dos Professores no âmbito do Ensino de Arte: estudos comparados entre Brasil e Argentina", projeto que recebeu, entre os anos de 2011 e 2013, financiamento da Coordenação de Aperfeiçoamento de Pessoal de Nível 
Superior (CAPES ${ }^{1}$ / Brasil) e do Ministerio de Ciencia, Tecnología e Innovación Productiva (MINCYT² / Argentina) através do Programa de Cooperação Científico e Tecnológico Argentino-Brasileiro (CAPES-MINCYT). Partiu-se, na construção deste artigo, dos pressupostos apontados por Fonseca da Silva, Hillsheim e Pera (2014) e Buján, Frade e Fonseca da Silva (2014).

O referido projeto integra, hoje, diferentes universidades: no Brasil, a Universidade do Estado de Santa Catarina (UDESC) ${ }^{3}$, a Universidade do Estado do Rio de Janeiro (UERJ) ${ }^{4}$; a Universidade do Paraná (UFPR) ${ }^{5}$, a Universidade do Amazonas (UFAM) ${ }^{6}$, a Universidade Federal do Mato Grosso do Sul (UFMS) ${ }^{7}$ e a Universidade Federal do Espírito Santo (UFES) ${ }^{8}$. Na Argentina, a Universidad Nacional de las Artes (UNA) ${ }^{9}$ e a Universidad Nacional de Rosário (UNR) ${ }^{10}$.

No estudo realizado entre 2011 e 2013, foi proposto um diagnóstico sobre a formação de professores de artes no Brasil e na Argentina a fim de conformar um estado da arte sobre esse domínio tendo como foco de análise do tema das inovações no processo de formação crítica de professores e pesquisadores. O propósito, naquele momento, foi construir um observatório bilateral capaz de produzir um diagnóstico da área. $\mathrm{Na}$ atualidade, como desdobramento desse trabalho, a proposta foi de constituir uma rede ${ }^{11}$ de pesquisadores na qual se articule uma série de pesquisas e estudos sistemáticos que colaborem para dar conta das condições em

1 Ver: <http://www.capes.gov.br>.

2 Ver: <http://www.mincyt.gov.ar>

3 Ver: $<$ http://www.udesc.br/>.

4 Ver: <http://www.uerj.br/>.

5 Ver: <http://www.ufpr.br/portalufpr/>.

6 Ver: <http://www.ufam.edu.br/>.

7 Ver: <http://www.ufms.br/>.

8 Ver: $<$ http://www.ufes.br/>.

9 Ver: <http://una.edu.ar/>.

10 Ver: <http://www.unr.edu.ar/>.

11 A referida rede foi criada no Chile durante a realização do IV Congresso Internacional Ciencias, Tecnologías y Culturas, Diálogo entre las disciplinas del conocimiento. Hacia el futuro de América Latina y el Caribe no Simpósio Latino-americano de Formação Docente em Artes: para uma rede colaborativa de investigadores com o nome de Red Latinoamericana de Investigadores en la Formaçión de Profesores en Artes - LAIFOPA 
que se desenvolve atualmente a formação de professores e pesquisadores nessa área específica do conhecimento, ampliando as possibilidades de inserção na América Latina. Ao mesmo tempo, o observatório se constitui como grupo de pesquisa permanente que aprofunda as análises desenvolvidas e em desenvolvimento.

É nesse contexto que diversas problemáticas vinculadas à formação dos professores de arte estão sendo estudadas no âmbito da pesquisa e pós-graduação. Mas, para compreender mais cabalmente como se configura o ensino das artes nos sistemas formais de ensino no nível superior, é necessário indagar sobre as políticas que regulam a formação dos professores e, em especial, a formação em artes visuais.

Fonseca da Silva (2010) afirma que, na trajetória das investigações sobre a formação de professores de artes, pouco tem sido escrito acerca das políticas públicas, argumentando que isso acontece porque, na maioria das vezes, essas políticas mudam de um governo para outro e não se tem conseguido desenvolver pesquisas sobre as modificações que elas imprimem na formação docente em artes. Agrega também que, na maioria dos estudos na linha de ensino de arte, o foco se dá sobre a prática de sala de aula sem que haja uma relação dessa prática com a legislação.

Outro aspecto que se soma a essa proposição da autora é que a área de arte se dedica pouco, ou quase nada, à problemática pedagógica da formação de professores de arte, entendendo este como um tema mais voltado à educação. Já a área de educação, na maioria dos estudos, como os desenvolvidos por Gatti e Barreto (2009) ou mesmo por Shiroma (2010), preocupa-se muito mais com a formação docente em geral e mesmo com a formação de professores pedagogos, de português e matemática, que numericamente ocupam maior parcela das preocupações entre os pesquisadores da área do que com a formação de professores de artes. Raríssimos estudos tocam no nome da disciplina, seja pela sua recente inserção no currículo escolar, seja pelo pequeno número de professores e créditos da disciplina na escola.

Considerando a amplitude do tema e a consequente necessidade de fazer um recorte, tomou-se como tarefa, neste trabalho, mapear as principais legislações que orientam e regulam, na atualidade, a formação dos professores de arte nos contextos 
argentino e brasileiro, com a intenção de aproximar-se, ainda que fosse inicialmente, desse complexo campo e identificar algumas tensões que se manifestam atualmente nesse domínio.

\section{APROXIMAÇÕES AO CONTEXTO ARGENTINO}

Uma primeira aproximação com as políticas públicas que regulam a educação no contexto argentino deve partir da Ley de Educación Nacional n²6.206 (LEN), vigente e de alcance nacional, na qual se definem, entre outras coisas, a estrutura, o governo e a administração do sistema educativo nacional, as obrigações do Estado em matéria educativa, os direitos e as obrigações dos cidadãos e os objetivos da política educativa nacional. A LEN foi sancionada em 14 de dezembro de 2006 e promulgada em 26 de dezembro do mesmo ano, substituindo, desse modo, a Lei Federal de Educação $n^{\circ} 24.195^{12}$.

\subsection{A Lei de Educação Nacional, o Instituto Nacional de Formação Docente e o Conselho Federal de Educação}

A LEN considera a educação e o conhecimento não só como bem público e um direito pessoal e social, que deve ser garantido pelo Estado, mas também como prioridade nacional e, como tal, constitui-se em política de Estado para construir uma sociedade mais justa e equitativa num contexto democrático.

A estrutura do sistema educativo nacional, definida por essa lei, compreende quatro níveis (Educação Inicial, Educação Primária, Educação Secundária e Educação Superior) e oito modalidades (Educação Técnico-Profissional, Educação Artística, Educação Especial, Educação Permanente de Jovens e Adultos, Educação Rural, Educação Intercultural Bilíngue, Educação em Contextos de Privação da Liberdade, e Educação Domiciliar e Hospitalar). Nota-se que a Educação Artística13

\footnotetext{
${ }^{12}$ A Lei $\mathrm{n}^{\circ} 24.195$ foi sancionada a 14 de abril de 1993, durante o primeiro mandato de governo do Presidente Carlos Saúl Menem, num contexto caracterizado pela implementação de políticas de matriz claramente neoliberal.

${ }^{13}$ Nome dado à disciplina de Ensino de Arte na Argentina.
} 
está contemplada como uma dessas oito modalidades. A respeito delas, destaca-se o artigo 17 da LEN:

\begin{abstract}
ARTÍCULO 17.- [...] A los efectos de la presente ley, constituyen modalidades del Sistema Educativo Nacional aquellas opciones organizativas y/o curriculares de la educación común, dentro de uno o más niveles educativos, que procuran dar respuesta a requerimientos específicos de formación y atender particularidades de carácter permanente o temporal, personales $\mathrm{y} / \mathrm{o}$ contextuales, con el propósito de garantizar la igualdad en el derecho a la educación y cumplir con las exigencias legales, técnicas y pedagógicas de los diferentes niveles educativos. (ARGENTINA, 2006).
\end{abstract}

Mais adiante, nos artigos 39, 40 e 41, abordam-se as especificidades da Educação Artística, a qual compreende:

a) a formação nas distintas linguagens artísticas para as crianças e adolescentes, em todos os níveis e modalidades;

b) a modalidade artística orientada à formação específica de nível secundário para aqueles/as alunos/as que escolham seguir essa orientação;

c) a formação artística realizada nos Institutos de Educação Superior, que compreendem as licenciaturas ${ }^{14}$ nas diversas linguagens artísticas para os distintos níveis de ensino e as carreiras artísticas específicas.

No tópico destinado à educação superior incluem-se quatro artigos (34 - 37) em que se define o tipo de instituições educativas que se ocuparão de ministrar a formação nesse nível, as legislações que o regularão, as instituições que o avaliarão e as competências das jurisdições sobre esse nível educativo.

De momento, destaca-se que o artigo 35 explicita que a educação superior será regulada pela Lei de Educação Superior (Lei no 24.521), a Lei de Educação TécnicoProfissional (Lei $n^{\circ} 26.058$ ) e pelas disposições da LEN no que tange aos Institutos de Educação Superior ${ }^{15}$.

\footnotetext{
${ }^{14} \mathrm{Na}$ Argentina, as carreiras de licenciatura são nomeadas de professorado.

15 Os Institutos de Educação Superior são instituições de nível superior não universitário que compreendem dois tipos de instituições educativas: a) os Institutos de Formação Docente, que assumem a formação docente inicial para os níveis inicial, primário e secundário, assim como
} 
Outro aspecto importante a considerar dentro da LEN no que respeita à formação docente é o indicado no segundo capítulo da quarta parte, em que se incluem oito artigos específicos sobre esse domínio. Ali, definem-se as finalidades da formação docente, destacando-se a construção de uma identidade docente com base na autonomia profissional, o vínculo com a cultura e a sociedade contemporânea, o trabalho em equipe, o compromisso com a igualdade e a confiança nas possibilidades de aprendizagem dos/das alunos/as (ARGENTINA, 2006, art. 71). Também se definem nesse capítulo, no artigo 73, os objetivos da Política Nacional de Formação Docente. Igualmente, no artigo 74 indica-se que o Ministério da Educação e o Conselho Federal de Educação acordarão:

a) as políticas e os planos (programas) de formação docente inicial;

b) as diretrizes para a organização e administração do sistema e os parâmetros da qualidade que orientem os desenhos curriculares (matrizes);

c) as ações que garantem o direito à formação continuada a todos/as os/as docentes do país, em todos os níveis e modalidades, e a gratuidade da oferta estatal de capacitação.

Mas, talvez, o mais importante a destacar em relação à formação docente e à criação do Instituto Nacional de Formação Docente (através do artigo 76 da LEN) é que, como organismo, seria responsável por, dentre outras coisas:

- promover políticas nacionais e diretrizes básicas curriculares para a formação docente inicial e continuada;

- desenvolver planos, programas e materiais para a formação docente inicial e continuada e para os cursos das áreas sócio-humanísticas e artísticas;

- coordenar as ações de seguimento e avaliação do desenvolvimento das políticas de formação docente inicial e continuada;

também programas de formação docente contínua; e b) os Institutos de Formação TécnicoProfissional, responsáveis pela formação de técnicos superiores em áreas específicas. Essas instituições podem ser, segundo indica a LEN no seu artigo 34, de gestão pública ou privada. 
- aplicar as regulações que regem o sistema de formação docente quanto à avaliação, autoavaliação e credenciamento de instituições e carreiras, validez nacional de títulos e certificações, em tudo o que não resulte de aplicação das disposições específicas referidas ao nível universitário da Lei $n^{\circ} 24.521$.

Finalmente, destaca-se que foi com essa lei (LEN) que se criou, também, o Conselho Federal de Educação, tal como se afirma no artigo 116:

\begin{abstract}
ARTÍCULO 116.- Créase el Consejo Federal de Educación, organismo interjurisdiccional, de carácter permanente, como ámbito de concertación, acuerdo y coordinación de la política educativa nacional, asegurando la unidad y articulación del Sistema Educativo Nacional. Estará presidido por el Ministro de Educación, Ciencia y Tecnología e integrado por las autoridades responsables de la conducción educativa de cada jurisdicción y tres (3) representantes del Consejo de Universidades, según lo establecido en la Ley $N^{\circ}$ 24.521. (ARGENTINA, 2006).
\end{abstract}

A criação desses novos organismos, como o Instituto Nacional de Formação Docente e o Conselho Federal de Educação, deu lugar à configuração de uma nova dinâmica na gestão, administração e governo do Sistema Educativo Nacional. Para completar o panorama dessa estrutura de base da política educativa nacional no contexto argentino, é preciso referir, tal como a seguir, a lei que define e regula a educação de nível superior.

\title{
2.2 A Lei de Educação Superior
}

A Lei n 24.521 (Lei Nacional de Educação Superior) foi promulgada em 7 de agosto de 1995 (Decreto $n^{\circ}$ 268/95) e constitui a lei vigente em que estão compreendidas todas as instituições de formação superior (sejam universitárias ou não) que formam parte do Sistema Educativo Nacional. Nesse sentido, a formação docente para todas as disciplinas, níveis e modalidades educativas, desenvolvida em instituições de gestão pública ou privada, inscreve-se dentro do estabelecido por essa Lei de Educação Superior (LES), que define ainda disposições específicas que configuram e regulam o sistema educativo superior da República Argentina, os fins e objetivos da educação superior, a estrutura do sistema, uma série de direitos e obrigações gerais tanto para os docentes quanto para os estudantes desse nível educativo, e normativas específicas tanto para as instituições universitárias públicas, 
para as privadas, quanto para as instituições de formação superior não universitárias (como eram definidas por essa lei).

É importante enfatizar essa distinção entre instituições de educação superior universitárias e não universitárias, primeiramente, porque a formação dos professores de arte na Argentina desenvolve-se em ambos os tipos de instituições. Por outra parte, enfatiza-se essa distinção porque a diferença de base em relação a cada tipo de instituição de formação superior encontra, em cada um dos casos, mecanismos diferenciados de regulação, avaliação e credenciamento dos cursos.

A respeito da educação superior não universitária define-se explicitamente no artigo 15 que é de responsabilidade das províncias, no caso da Argentina, assim como ao da cidade de Buenos Aires, o Governo e a organização da educação superior não universitária, em seus respectivos âmbitos de competência, assim como ditar normas que regulem a criação, competência, modificação ou fechamento de instituições desse tipo dentro de suas jurisdições. Nessa direção, indica-se a ingerência que esses governos têm sobre a definição e configuração das estruturas dos cursos, inclusive os que formam professores que atuam na disciplina de Educação Artística. No entanto, no artigo 23 indica-se que os planos de estudo (matrizes curriculares) das instituições de formação docente de caráter não universitário serão estabelecidos respeitando os conteúdos básicos comuns para a formação docente que sejam acordados no Conselho Federal de Cultura e Educação e que a validez nacional dos títulos estará sujeita ao prévio reconhecimento desses planos de estudo pela instância que seja determinada por aquele Conselho.

Sobre a educação superior universitária, um dos principais artigos formulados em relação ao assunto que aqui se ocupa é o 29, que trata da autonomia acadêmica e institucional das instituições universitárias. Além de incluir importantíssimas disposições que garantem a autonomia de gerenciamento das universidades, mencionam-se nesse artigo, entre outras, as seguintes atribuições que fazem parte de sua autonomia acadêmica: criar cursos universitários de graduação e pósgraduação e formular e desenvolver seus planos de estudo (matrizes curriculares). 
No artigo 30 da LES, contemplando uma situação extrema, afirma-se que as instituições universitárias nacionais poderiam sofrer intervenções somente pelo Honorável Congresso da Nação (ou durante seu recesso e ad referendum dele, pelo Poder Executivo Nacional) por prazo determinado (não superior a seis meses) e só por algumas das seguintes causas: a) conflito insolúvel dentro da instituição que faça impossível seu normal funcionamento, b) grave alteração da ordem pública, ou c) manifesto descumprimento da LES. No entanto, a intervenção nunca poderá menosprezar a autonomia acadêmica garantida pela LES.

Nessa lei se estabelece também que os cursos de graduação e de pósgraduação serão avaliados e credenciados pela Comisión Nacional de Evaluación y Acreditación Universitaria (CONEAU), o qual é um organismo descentralizado que funciona em jurisdição do Ministério da Educação (ARGENTINA, 1995, artigo 46).

Outro aspecto interessante é que no artigo 43 da LES explicita-se que, quando se tratarem de títulos correspondentes a profissões regulamentadas pelo Estado cujo exercício possa comprometer o interesse público, pondo em risco de modo direito a saúde, a segurança, os direitos, os bens ou a formação dos habitantes, será requerido que se respeitem os seguintes requisitos: a) os planos de estudo deverão considerar os conteúdos curriculares básicos e os critérios sobre intensidade da formação prática que estabeleça o Ministério da Educação, em acordo com o Conselho de Universidades; e b) as carreiras respectivas deverão ser credenciadas periodicamente pela CONEAU ou por entidades privadas constituídas com esse fim e devidamente reconhecidas.

\subsection{Orientações curriculares para a formação docente: uma política federal para a formação docente}

Desde que foi sancionada a Lei de Educação Nacional na Argentina e com a criação, a partir desse momento, do Conselho Federal de Educação (CFE) e do Instituto Nacional de Formação Docente (INFD), tem sido desenvolvida uma profícua atividade em matéria de construção federal de políticas para a formação docente no país. Isso é o que se verifica ao revisar as documentações e resoluções formuladas 
por esses organismos para os quais a formação docente constitui um eixo fundamental para o desenvolvimento social do país.

Nesse sentido, cabe destacar, primeiramente, a formulação dos referenciais Curriculares Nacionais para a Formação Docente Inicial (Resolução CFE n²4/07), as normativas destinadas às titulações para as carreiras de formação docente (Resolução CFE $n^{\circ}$ 74/08), a criação das licenciaturas de Educação Superior (Resolução CFE n 83/09), a formulação do Plano Nacional de Formação Docente para o período 2012-2015 (Resolução CFE n 167/12), dentre outras disposições gerais e, especificamente, no que se refere à formação de professores de arte, as Recomendações para a Elaboração de Desenhos Curriculares para as licenciaturas em Educação Artística (INFD, 2009).

Essas normativas, atualmente vigentes, têm alcance nacional e inscrevem-se dentro do formulado na Lei de Educação Nacional (LEN). Sua finalidade é organizar e regulamentar a complexidade que comporta o sistema de formação docente no país considerando as necessidades e requerimentos atuais da formação dos professores na contemporaneidade, produzir uma articulação federal nesse domínio, planificar o desenvolvimento do sistema e de sua oferta - entre outras questões prioritárias - que se formulam ante um diagnóstico de fragmentação e marcada heterogeneidade na formação dos professores nas diversas disciplinas e nas distintas regiões do território nacional argentino.

É possível considerar que, num primeiro olhar, muitas das diretrizes e orientações parecem referir-se aos Institutos Superiores de Formação Docente (não universitários), no entanto, na Resolução n²4/07 do CFE indica-se que as Diretrizes Curriculares Nacionais alcançam, também, as propostas de formação docentes dependentes das universidades (parágrafo 14) e, nessa direção, explicita-se que

Las Universidades, responsables por la formación inicial de Profesores en una importante variedad de disciplinas, deberán ajustar sus propuestas a los Lineamientos Curriculares Nacionales y considerar las propuestas Jurisdiccionales de su ámbito de actuación, distinguiendo con claridad aquello que corresponde a la formación del Profesorado de los otros requerimientos curriculares de las distintas Licenciaturas de corte académico. En otros términos, sus currículos para la formación de Profesores no se circunscribirán a un agregado final de materias pedagógicas, sino al diseño y desarrollo de una propuesta curricular específica. Asimismo, los diseños universitarios 
deberán considerar una sólida articulación con las escuelas, tal como se destaca en estos Lineamientos (ARGENTINA, 2007, parágrafo 21).

Essas últimas indicações interpelam, de maneira direta, as universidades e, mais especificamente, a formação docente desenvolvida nelas. Os alcances da nova configuração e regulação da formação docente articulam-se, assim, no interior de uma política nacional de formação docente que está demandando uma revisão das matrizes curriculares dos cursos de formação docente nas universidades e, assim, uma maior articulação com a comunidade local.

\subsection{Primeiras considerações}

Cabe destacar, primeiramente, que é possível distinguir três níveis de decisão e desenvolvimento curricular, como estabelece a Resolução CFE n 24/07:

a) A regulação nacional, que define os marcos, princípios, critérios e formas de organização dos desenhos curriculares jurisdicionais e da gestão do currículo.

b) A definição jurisdicional, através do desenho e desenvolvimento do plano de formação provincial e seus correspondentes desenhos curriculares, a partir das Diretrizes Curriculares Nacionais.

c) A definição institucional, elaborada pelos institutos formadores, que permite a definição das propostas e ações de concreção local, considerando as potencialidades, necessidades e possibilidades do contexto específico, as capacidades institucionais instaladas, os projetos educativos articulados com as escolas da comunidade e as propostas de atividades complementárias para o desenvolvimento cultural e profissional dos futuros docentes.

Nesse sentido, as Diretrizes Curriculares Nacionais para a Formação Docente Inicial se inscrevem no primeiro desses níveis e correspondem às instituições responsáveis por desenvolver a formação docente e elaborar suas propostas de formação em relação a tais diretrizes. Por sua parte, o documento do INFD (2009) enfatiza o seu caráter e estatuto, no sentido de constituir recomendações para a estruturação das propostas de formação docente em artes. 
Se esses aspectos são considerados, em linhas gerais, de maneira mais harmônica nas instituições superiores não universitárias que se ocupam com a formação dos professores de artes apresentando em suas propostas curriculares um maior grau de homogeneidade por serem reguladas a nível provincial ou municipal, nas instituições universitárias parece que são produzidas maiores tensões em relação a essas legislações e marcos regulatórios.

O centro da tensão está localizado no grau de alcance dessas disposições que, em parte, entram em conflito com a autonomia acadêmica que gozam por lei (LES) e que Ihes dá o direito de criar cursos (de graduação e pós-graduação) formulando e definindo seus planos de estudo (matrizes curriculares) autonomamente. Registra-se, nesse sentido, uma grande heterogeneidade em suas propostas de formação docente, aproximando-se ou afastando-se em graus diversos dessas disposições, as quais são consideradas, muitas vezes, como uma ameaça limitante dessa autonomia ou diretamente como um avassalamento da autonomia universitária.

\section{APROXIMAÇÕES AO CONTEXTO BRASILEIRO}

As reformas ocorridas nas últimas décadas na educação brasileira sofrem, de modo geral, influências internacionais tanto de organismos privados a serviço do capital, como de instituições, como a UNICEF, que buscam homogeneizar as políticas culturais e educacionais em diferentes partes do mundo, principalmente definindo o modelo de educação dos chamados "países em desenvolvimento". Embora nossas políticas não tenham nenhuma originalidade é necessário analisar como se constitui as relações entre as políticas públicas e o modelo proposto para o sistema nacional de educação.

\subsection{A Lei de Diretrizes e Bases da Educação Nacional - Lei n 9.394/96}

A Lei de Diretrizes e Bases da Educação Nacional tem como objetivo definir os princípios e formas de funcionamento para o ensino brasileiro. A existência de um sistema educacional nacional auxilia a articulação desse processo, garantindo também ações voltadas para os aspectos regionais. No entanto, a meta de universalização da educação básica ainda esbarra em aspectos primordiais no 
tocante ao financiamento. Para Saviani (1998), uma política social efetiva necessita considerar um aporte financeiro para a área social condizente com o aporte destinado à área econômica. A intensificação das lutas em torno do papel do Estado como gestor da educação de forma eficiente e com probidade administrativa também faz parte do processo de garantia para uma efetiva universalização do sistema educacional. Por último, o autor propõe a separação entre a política social e os índices de desempenho econômico, situação que se vivencia nesse exato momento com os cortes da "Pátria Educadora" em função da crise político-financeira que o país atravessa. Ressalta-se que esse autor definiu tais tópicos nos primeiros anos de aprovação da nova LDB, no final da última década do século XX, mas eles servem exatamente para pensar 0 processo de produção das políticas públicas nos anos atuais.

Outro elemento da conjuntura atual é o documento do currículo mínimo para a educação básica, proposto pelo Ministério da Educação (MEC) a partir de uma proposta redigida por um conjunto de consultores, que vai até dezembro de 2015, ser alvo de uma consulta pública. A universalização dos conteúdos, bandeira defendida pelos signatários da pedagogia histórico-crítica, deveria garantir que o estudante, em sua trajetória escolar, tivesse assegurado o aprendizado de conteúdos necessários à sua formação, garantindo o modelo proposto por Gramsci a partir das ideias de Marx acerca de uma formação integral, centrada no conceito de omnilateralidade como aponta Nosella (1992).

O que se vê no novo documento governamental é uma colcha de retalhos produzida de forma aligeirada que não dá conta, ao menos na área de artes, da complexidade das áreas abordadas e, inclusive, do acúmulo da área na organização e distribuição dos conhecimentos.

O tema da formação inicial e continuada está situado no capítulo VI da LDB, definindo as características necessárias do educador e os níveis de atuação, bem como as exigências de formação para a atuação prática. Define, igualmente, os fundamentos necessários para a formação e o lócus de formação inicial dos profissionais. Nesse tópico, apresentam-se as características dos institutos de formação que se diferenciam das universidades pelo distanciamento da pesquisa. Acredita-se que afastar a formação de professores dos centros de pesquisa, além de 
empobrecer a formação, dispersa recursos públicos para instituições privadas. A mudança do lócus de formação de professores dos centros de educação para os institutos marca, de forma mais efetiva, a fragilidade da formação que se espera do professor.

No artigo 67 da LDB é abordado o tema da valorização profissional a partir da ênfase na construção dos estatutos e planos de carreira dos sistemas públicos de ensino. Faz-se necessário observar o movimento dos governos em relação a essa valorização, com destaque para a dificuldade na implementação do piso nacional, do tempo remunerado de preparação de aulas, da formação continuada e, principalmente, da formação em nível de pós-graduação. Esses são temas pelos quais os sindicatos de professores têm lutado ao longo da sua trajetória política. Há uma relutância dos governantes em colocar em prática tais direitos, que já foram, reiteradas vezes, apontados nas políticas públicas. Essa incorporação dos direitos do magistério seria, de fato, uma ação para demonstrar uma valorização e, ao mesmo tempo, tornar a carreira atrativa e instigadora.

Aprovada no ano de 1996, a LDB tramitou por mais de dez anos no congresso sendo alvo da correlação de forças presentes na Câmara de Deputados e no Senado Federal. Ora a legislação pendia para os interesses do fórum em defesa da escola pública, ora para os grupos privados que defendiam os interesses das escolas particulares. Sobre esses embates, Saviani (1997) apresenta extensa e contundente discussão. Toda a disputa presente no processo de proposição da LDB caminhou par e passo com as proposições neoliberais presentes na educação, como aponta Arce (2001) ao analisar os documentos propostos pelo MEC diagnosticando um viés pósmoderno e neoliberal como base dos documentos. Estudos mais atuais, como os organizados por Evangelista (2014), corroboram com a percepção de que as políticas públicas enfatizam esse quadro de desqualificação da profissão docente e, por consequência, da dissipação da escola como espaço de socialização do conhecimento para as camadas populares, na medida em que não definem as formas de financiamento das propostas, ou as fazem de forma a deixar brechas para o descumprimento. 
Diversas modificações foram inseridas no texto da Lei n $9.394 / 96$ ao longo da última década, algumas delas dizem respeito aos interesses da área de ensino de artes, como a Lei $n^{\circ} 10.639 / 2003$, que altera a LDB inserindo a obrigatoriedade do ensino da história e cultura negra na escola, em especial para os professores de Artes (Educação Artística, como descrita no texto da lei), e a inserção dos conteúdos de cultura indígena por meio da Lei no $11.645 / 2008$. Outra modificação inserida na LDB é a obrigatoriedade do ensino da música na escola, prevista na Lei no 11.769/2008 não como único conteúdo, substituindo o ensino das artes, mas como conteúdo adicional ao ensino já realizado na escola. Essas mudanças alteram também a formação inicial nos cursos de graduação, bem como os planos de educação continuada das redes de ensino. Tramita também no congresso nacional o PL 7.032/2010, que pretende reformular o modelo de formação em artes no Brasil, alteração esta proposta pela Federação dos Arte-Educadores do Brasil (FAEB), reconhecendo o direito e a necessidade de oferta das áreas de música, artes visuais, teatro e dança como conteúdos independentes no currículo escolar a partir de professores habilitados em cada uma das linguagens, o que requer um aumento de carga horária no currículo escolar.

Os currículos das licenciaturas em Artes Visuais, além de obedecerem a LDB, devem considerar as legislações específicas sobre a formação de professores para a educação básica, que são a Resolução de 04 de julho de 2010, que define as Diretrizes Curriculares Nacionais para a Educação Básica, que, entre outros objetivos, buscam orientar os cursos que formam professores para a educação básica, bem como as Diretrizes Curriculares Nacionais do Curso de Graduação em Artes Visuais (Resolução no 01, de 16 de janeiro de 2009), esta incidindo tanto para a formação do professor quanto do artista. A respeito dessas diretrizes, encontra-se ampla análise nos estudos de Fonseca da Silva (2010).

Recentemente, em julho de 2015, foi aprovada a Resolução n 02/2015, intitulada de Diretrizes Curriculares Nacionais para a formação inicial em nível superior (cursos de licenciatura, cursos de formação pedagógica para graduados e cursos de segunda licenciatura) e para a formação continuada. Aqui, será feita uma análise do documento e, ao final, são estabelecidas relações com a legislação argentina. 


\title{
3.2 Resolução $\mathrm{n}^{\circ}$ 02, de $1^{\circ}$ de julho de 2015
}

A Resolução $n^{\circ}$ 02, de $1^{\circ}$ de julho de 2015 , revoga os seguintes documentos fartamente analisados do âmbito educacional: "Art. 25 - Esta Resolução entra em vigor na data de sua publicação, revogadas as disposições em contrário, em especial a Resolução CNE/CP oㅡ 2, de 26 de junho de 1997, a Resolução CNE/CP № 1, de 30 de setembro de 1999, a Resolução CNE/CP № 1, de 18 de fevereiro de 2002 e suas alterações, a Resolução CNE/CP № 2, de 19 de fevereiro de 2002 e suas alterações, a Resolução $\mathrm{n}^{\circ}$ 1, de 11 de fevereiro de 2009, e a Resolução ํㅜ 3, de 7 de dezembro de 2012". (BRASIL, 2015).

A referida resolução inicia apresentando 13 princípios que buscam delinear os pressupostos para o projeto nacional da educação brasileira. Destaca-se, em especial, o terceiro que diz:

\begin{abstract}
CONSIDERANDO que a igualdade de condições para o acesso e a permanência na escola; a liberdade de aprender, ensinar, pesquisar e divulgar a cultura, o pensamento, a arte e o saber; o pluralismo de ideias e de concepções pedagógicas; o respeito à liberdade e o apreço à tolerância; a valorização do profissional da educação; a gestão democrática do ensino público; a garantia de um padrão de qualidade; a valorização da experiência extraescolar; a vinculação entre a educação escolar, o trabalho e as práticas sociais; o respeito e a valorização da diversidade étnico-racial, entre outros, constituem princípios vitais para a melhoria e democratização da gestão e do ensino. (BRASIL, 2015, grifo nosso).
\end{abstract}

Observa-se que este princípio enfatiza a necessidade da liberdade de aprender, ensinar, pesquisar e divulgar a cultura, o pensamento, a arte entre outros aspectos importantes, como a valorização do profissional, a gestão democrática, a qualidade a vinculação entre a educação escolar, o trabalho e as práticas sociais, bem como os aspectos relativos à Lei $n^{\circ} 10.639 / 2003$, que defende a perspectiva da visibilidade da história e cultura africana e afro-brasileira no currículo escolar.

A resolução está disposta em oito capítulos, cada qual apresentando um conteúdo específico. O primeiro, intitulado "Das Disposições Gerais", apresenta os principais temas de forma mais ampla. Os aspectos orientadores dos demais tópicos funcionam como uma introdução da resolução à guisa de situar o leitor acerca das proposições iniciais. Alguns dos principais conceitos aparecem enunciados nesse 
capítulo, como o de educação no primeiro parágrafo, artigo terceiro, do capítulo um. Destaca-se ainda que o tema da interdisciplinaridade é um dos fios condutores da resolução aparecendo reiteradas vezes no texto, no entanto, não ganha uma descrição que possibilite identificar a que modelo de interdisciplinaridade está se referindo. Ressalta-se para esta análise o texto de Frigotto (2008, p. 41):

\begin{abstract}
A questão da interdisciplinaridade, ao contrário do que se tem enfatizado, especialmente no campo educacional, não é sobretudo uma questão de método de investigação, e nem de técnica didática, ainda que se manifeste enfaticamente neste plano. Vamos sustentar que a questão da interdisciplinaridade se impõe como necessidade e como problema fundamentalmente no plano material histórico-cultural e no plano epistemológico.
\end{abstract}

A compreensão da totalidade como categoria central de interpretação da realidade social sustenta a interdisciplinaridade como necessidade imperativa para a construção do conhecimento social. Para o referido autor, o processo do conhecimento vem marcado pelas condições históricas dos sujeitos, seus interesses, posições de classe, assim, o conhecimento não é neutro "[...] porque as relações que ele tenta aprender não são neutras." (FRIGOTTO, 2008, p. 46).

O documento apresenta a concepção de parcerias entre os sistemas de ensino e as universidades. Aspecto que merece uma análise mais aprofundada no sentido de perceber se essa parceria se daria numa perspectiva da relação com o tripé ensino, pesquisa e extensão, defendido pelas universidades, ou se seria uma forma de desresponsabilizar os governos perante sua tarefa de investir financeiramente na formação de professores.

No capítulo dois, intitulado de "Formação dos profissionais do magistério para a educação básica: base comum nacional", são apresentadas as características da formação inicial. O seu artigo quinto destaca que

A formação de profissionais do magistério deve assegurar a base comum nacional, pautada pela concepção de educação como processo emancipatório e permanente, bem como pelo reconhecimento da especificidade do trabalho docente, que conduz à práxis como expressão de articulação entre teoria e prática e à exigência de que se leve em conta a realidade dos ambientes das instituições educativas da educação básica e da profissão, para que se possa conduzir o (a) egresso (a)[...] (BRASIL, 2015). 
Na sequência, esse artigo quinto apresenta nove tópicos com as características formativas do egresso. Destacam-se algumas palavras-chaves desses tópicos:

[...] à integração e interdisciplinaridade curricular [...]; à construção do conhecimento[...]; ao acesso às fontes nacionais e internacionais de pesquisa[...]; às dinâmicas pedagógicas[...]; à elaboração do processo de formação em consonância com as mudanças educacionais e sociais[...]; ao uso competente das Tecnologias de Comunicação e Informação (TIC) [...]; à promoção de espaços para a reflexão crítica sobre as diferentes linguagens e seus processos de construção[...]; à consolidação da educação inclusiva através do respeito às diferenças [...]; à aprendizagem e ao desenvolvimento de todos (as) os (as) estudantes durante o percurso educacional [...]. (BRASIL, 2015).

No terceiro capítulo, a resolução apresenta "Do (a) egresso (a) da formação inicial e continuada", definindo, de um lado, o repertório necessário para o egresso após a realização de sua formação, incluindo diferentes habilidades, dentre elas a "[...] sensibilidade afetiva e estética" (BRASIL, 2015). Do mesmo modo, o capítulo prevê que o professor esteja apto a conhecer a instituição educativa reconhecendo-a, nas palavras da resolução, "[...] como organização complexa na função de promover a educação para e na cidadania" (BRASIL, 2015). Diz ainda que os princípios da interdisciplinaridade deverão permitir "[...] a pesquisa, a análise e a aplicação dos resultados de investigações de interesse da área educacional e específica" para também estar apto a "[...] atuação profissional no ensino, na gestão de processos educativos e na organização e gestão de instituições da educação básica" (BRASIL, 2015).

Outro tópico inserido na Resolução $n^{\circ}$ 02/2015, em seu capítulo três, diz respeito à formação necessária prevista nos cursos de formação que articulem o Projeto Pedagógico dos Cursos (PPC), o Projeto Pedagógico Institucional (PPI) e o Plano de Desenvolvimento Institucional (PDI), todos articulados com as dimensões e características da iniciação à docência, definindo, desse modo, nove tópicos que evidenciam esse aprimoramento. Situam-se, assim, algumas palavras-chaves nesses tópicos apresentadas:

[...] estudo do contexto educacional [...]; desenvolvimento de ações que valorizem o trabalho coletivo [...]; planejamento e execução de atividades nos espaços formativos [...]; [...] participação nas reuniões da escola [...]; análise do processo pedagógico e de ensino aprendizagem [...]; leitura e discussão de referenciais teóricos contemporâneos educacionais [...]; cotejamento e 
análise de conteúdos que balizam e fundamentam as diretrizes curriculares para a educação básica [...]; desenvolvimento, execução, acompanhamento e avaliação de projetos educacionais [...]; e sistematização e registro das atividades em portfólio ou recurso equivalente de acompanhamento. (BRASIL, 2015).

Finalmente, o artigo oitavo destaca as habilidades que o egresso deverá possuir após ter desenvolvido os conteúdos propostos no artigo sétimo ampliando, de forma efetiva, as responsabilidades do professor em sua atuação.

No capítulo quatro da referida lei, "Da formação inicial do magistério da educação básica em nível superior", fica evidenciado o lócus da formação de professores para a educação básica em três modalidades, a primeira delas em cursos de licenciatura, a segunda em cursos de formação pedagógica para graduados não licenciados e a terceira em cursos de segunda licenciatura.

A modalidade preferencialmente ofertada para a formação inicial será presencial, "[...] com elevado padrão acadêmico, científico e tecnológico e cultural" (BRASIL, 2015). A resolução destaca ainda a necessária disponibilidade de recursos estruturais, humanos e pedagógicos capazes de possibilitar diferentes experiências de formação. Propõe, igualmente, a formação de núcleos de formação geral, de aprofundamento e diversificação e de estudos integradores para o enriquecimento curricular. Todos os cursos de licenciatura necessitam organizar seus currículos levando em consideração essa organização para adequar-se à resolução.

No capítulo cinco, "Da formação inicial do magistério da educação básica em nível superior: estrutura e currículo", apresenta-se a organização curricular definindose a carga horária mínima de três mil e duzentas horas de atividades exercidas, organizadas em oito semestres, no mínimo, ou quatro anos. Nessa organização, fica determinada a carga horária de estágio de quatrocentas horas de prática como componente curricular; outras quatrocentas horas para estágio supervisionado; e duas mil e duzentas horas de atividades formativas; além de mais duzentas horas de atividades de aprofundamento escolhidas pelos estudantes.

No capítulo cinco é ressaltada, em seu parágrafo dois, artigo treze, a determinação de que 
Os cursos de formação deverão garantir nos currículos conteúdos específicos da respectiva área de conhecimento ou interdisciplinares, seus fundamentos e metodologias, bem como conteúdos relacionados aos fundamentos e metodologias, direitos humanos, diversidades étnico-racial, de gênero, sexual, religiosa, de faixa geracional, Língua Brasileira de Sinais (Libras), educação especial e direitos educacionais de adolescentes e jovens em cumprimento de medidas socioeducativas. (BRASIL, 2015).

Esse parágrafo insere diretamente nos cursos de licenciaturas conhecimentos voltados à formação do educador, comuns à área da educação. Talvez uma forma de garantir a produção de relações entre esses conteúdos e os conteúdos da área de formação fosse que estes estivessem presentes também nas disciplinas de conteúdo específico.

Ainda no capítulo cinco, a resolução também aborda os modelos de formação considerando a formação pedagógica de graduados não licenciados, tema bastante polêmico considerando-se que não há uma definição precisa de que áreas podem ser consideradas afins. Fica a critério da IES ofertante do curso analisar se há relação entre o curso habilitado e a pretensão do candidato.

"Da Formação Continuada dos Profissionais do Magistério" é o título do capítulo VI da resolução analisada, que define em seu artigo 16 que

\begin{abstract}
A formação continuada compreende dimensões coletivas, organizacionais e profissionais, bem como o repensar do processo pedagógico, dos saberes e valores, e envolve atividades de extensão, grupos de estudos, reuniões pedagógicas, cursos, programas e ações para além da formação mínima exigida ao exercício do magistério na educação básica, tendo como principal finalidade a reflexão sobre a prática educacional e a busca de aperfeiçoamento técnico, pedagógico, ético e político do profissional docente. (BRASIL, 2015).
\end{abstract}

Da mesma forma, esse capítulo caracteriza essa formação como um processo articulado, vinculado aos sistemas e às redes de ensino, ao projeto pedagógico e aos problemas e desafios do contexto escolar. Já o artigo 17 determina os tipos de atividades, como cursos de atualização, de extensão, aperfeiçoamento, especialização, mestrado e doutorado, objetivando a aprendizagem de novos saberes e práticas direcionados à educação básica em suas diferentes modalidades. Igualmente, determina o Fórum Estadual Permanente de Apoio à Formação Docente que, em conjunto com os sistemas de ensino e as instituições de educação básica, 
será desenvolvido um plano de formação em consonância com as políticas de valorização a serem efetivadas pelos sistemas de ensino.

No capítulo VII, "Dos Profissionais do Magistério e sua Valorização", no artigo 18 fica definida a responsabilidade pela garantia de políticas de valorização compartilhadas entre sistemas de ensino, redes e instituições educativas, além do plano de carreira, segundo as normativas em vigor. No parágrafo oito desse artigo, além do plano de carreira e salário, fica estipulada a necessidade de condições de dedicação exclusiva, ou tempo integral, a ser cumprida em um único estabelecimento de ensino, destinando-se um terço da carga horária de trabalho para outras atividades pedagógicas determinadas em oito diferentes possibilidades, desde a preparação de aulas até outras atividades relativas à comunidade.

O capítulo sete também define a entrada por concurso público, pagamento do piso nacional, diferenciação salarial por titulação e revisão salarial anual dos vencimentos conforme a lei do piso. Entre outros aspectos, esse capítulo também aborda as formas de organização e gestão da educação básica.

Nas "Disposições transitórias", capítulo oito, fica determinado que os cursos têm o prazo de dois anos para adaptarem-se à Resolução $n^{\circ}$ 02, de 01 de julho de 2015.

\section{SEGUNDAS CONSIDERAÇÕES}

Após a tentativa de sistematizar o documento em questão apresentando-o sinteticamente, parece crucial destacar que a peça legislativa é fruto da correlação de forças entre os movimentos sociais na luta pelos direitos da educação e seus profissionais e a correlação de forças possíveis nas disputas dentro do congresso. Saviani (2011) destaca a importância de conhecer a legislação, pois os documentos são peças-chaves para identificar os interesses presentes nas entrelinhas dos documentos. Segundo o autor, há que se prestar atenção nas ideologias presentes nos documentos. "[...] penso que a questão da ideologia seria mais bem caracterizada como expressão de interesses. Isso significa que, conforme as posições que ocupam na sociedade, as classes e os grupos sociais constroem uma visão de realidade." 
(SAVIANI, 2011, p. 37), pois os documentos buscam tornar verdade as ideologias dos grupos dominantes.

Considera também Saviani (2011) que a educação é um instrumento usual das camadas dominantes para colocar suas ideias em prática. Talvez esse fenômeno se concretize pela capacidade de aglutinação da escola, de padronização de comportamentos e da existência de políticas uniformizadoras, facilitando, assim, os processos de uniformização. Os movimentos de resistência a essa ideologia dominante buscam criar espaços de disputa no interior dos processos de produção das peças legislativas. $O$ autor ressalta a necessidade de identificar o espaço crítico, possível de ocupação pelos setores que buscam uma contra-hegemonia. Ele ressalta, da mesma forma, que o estudo da legislação é central para a compreensão crítica do modo como o sistema de ensino se organiza.

Para Saviani (2011, p. 40) "[...] na análise da legislação é importante distinguir o texto e o contexto, as linhas e as entrelinhas, a letra e o espírito". Diante dos aspectos apresentados, finaliza-se o entrelaçamento entre as análises argentinas e brasileiras buscando identificar se as políticas fazem parte de um conjunto mais amplo, ou se cada cenário aponta para soluções peculiares.

\section{CONSIDERAÇÕES FINAIS}

Neste trabalho, abordou-se o âmbito geral em que está inscrita a formação de professores de artes nos contextos argentino e brasileiro, pondo foco nas políticas que regulam e orientam a formação docente. No caso argentino, as recomendações curriculares mais atuais, orientadas de maneira específica na formação de professores nas diferentes linguagens artísticas, incluem um amplo espectro de problemáticas aos efeitos de atender às demandas atuais dos contextos diversos e extremadamente complexos. Mas as recomendações e orientações curriculares referidas de maneira específica à formação de professores de artes, dadas as características e o modo de organização do sistema de educação superior argentino (subdividido em instituições universitárias e instituições não universitárias de nível superior, além da distinção entre instituições de gestão pública e de gestão privada) fazem com que as normativas não sejam implementadas de maneira homogênea. 
Como já foi referido, a principal problemática que se apresenta nesse sentido, no âmbito universitário, tem a ver com a autonomia universitária e seus alcances nas definições curriculares, produzindo-se uma tensão e entrando em conflito com algumas disposições e normativas. Cabe considerar, nesta direção, que grande parte da oferta de formação docente em artes no contexto argentino não está concentrada no âmbito universitário e que, no âmbito das instituições de formação superior que não estão inscritas no âmbito universitário, esse particular não constitui uma tensão tão aguda. Este último tem a ver precisamente com as condições de desenvolvimento das políticas educativas em âmbitos de implementação claramente diferenciados cujas possibilidades de autogoverno também se inscrevem em condições particularmente diferenciadas. A formação de professores de artes no âmbito universitário apresenta, desse modo, uma grande heterogeneidade (BUJÁN, 2013) que está plenamente vinculada com as culturas institucionais e que se manifesta claramente nos modos em que estão compostas e organizadas as matrizes curriculares de cada um dos cursos, nos modos em que são priorizadas algumas perspectivas e domínios disciplinares e, finalmente, na distribuição da carga horária em áreas de formação geral e específica da formação docente e das linguagens artísticas. Essas configurações particulares, que dão lugar a estudos específicos, nesse nível de decisões no âmbito institucional, implicarão finalmente possibilidades e restrições individualizadas com alcances manifestos não somente nos âmbitos restritos de cada caso, mas também como parte das condições gerais de desenvolvimento do campo da arte-educação no contexto local.

Muitas similaridades são percebidas nas duas realidades, principalmente ao se perceber a implantação de um projeto neoliberal de educação crescente na América Latina a partir de 1990 e do ponto estratégico que a formação de professores ocupa nesse cenário como estratégia de efetivação do projeto proposto. Alguns aspectos em comum que se tornam grandes desafios para ambos os contextos têm a ver com o trabalho desde a diversidade e o fomento de uma educação que inclua as práticas educativas, de fato, em contextos cada vez mais diversos e complexos, em atenção às necessidades especiais e sociais, além das diferentes realidades sociais em que são desenvolvidas. 
A legislação, sozinha, não possibilita uma leitura adequada da realidade, por isso é necessário levar em conta diferentes estudos acadêmicos no âmbito do observatório que auxiliem a vislumbrar e ampliar dados acerca da formação. Ademais, é importante a participação ativa dos professores de artes visuais que, com seus depoimentos e com a intenção de reconhecimento de sua realidade, auxiliam a compreender melhor o cenário atual da formação no ensino superior, a sala de aula e vice-versa.

Finaliza-se destacando que o tema da formação polivalente é objeto de reflexão nos dois países, assim como a formação aligeirada e funcional, propiciada nos institutos de educação, principalmente nos de gestão privada, exigindo que os professores se organizem para reivindicar seus direitos. No cenário brasileiro, destaca-se, em relação à legislação analisada, a ampliação da responsabilidade das universidades, vistas como participantes institucionais. Por outro lado, o mesmo documento não aponta as implicações e o financiamento desse envolvimento, fato que coloca a autonomia universitária como elemento de debate mais uma vez.

Dentro do exposto, colocam-se novos desafios tanto para o Observatório da Formação de Professores de Artes, quanto para a Red de Investigadores frente à necessidade de novos estudos tomando a América Latina como foco de análise e buscando os pontos de interseção, bem como práticas diferenciadas de formação e resistência aos modelos neoliberais de formação de professores de artes.

\section{Referências}

ARCE, A. Compre o kit neoliberal para a educação infantil e ganhe grátis os dez passos para se tornar um professor reflexivo. Educação e Sociedade. Campinas/SP, v. 74, n.XII, 2001. p. 251-284.

ARGENTINA. Ley Federal de Educación $n^{\circ}$ 24.195, de 14 de abril de 1993. Disponível em: <http://www.coneau.edu.ar/archivos/648.pdf>. Acesso em: 18 nov. 2015.

ARGENTINA. Ley Nacional de Educación Superior nํ24.521, de 20 de julho de 1995. Disponível em: <http://www.coneau.edu.ar/archivos/447.pdf>. Acesso em: 18 nov. 2015.

ARGENTINA. Ley de Educación Técnico Profesional n 26.058, de 7 de setembro de 2005. Disponível em: <http://portal.educacion.gov.ar/consejo/files/2009/12/ley26058.pdf>. Acesso em: 18 nov. 2015.

ARGENTINA. Ley de Educación Nacional no 26.206, de 14 de dezembro de 2006. LEN. Disponível em: $<\mathrm{http}: / /$ www.me.gov.ar/doc_pdf/ley_de_educ_nac.pdf>. Acesso em: 18 nov. 2015.

ARGENTINA. Consejo Federal de Educación (CFE). Resolução no 24, de 7 de novembro de 2007.Disponívelem:<http://repositorio.educacion.gov.ar:8080/dspace/bitstream/handle/123456789/53 990/12924.pdf?sequence=1>. Acesso em: 18 nov. 2015. 
ARGENTINA. Consejo Federal de Educación (CFE). Resolução no 74, de 16 de dezembro de 2008. Disponível em: <http://www.me.gov.ar/consejo/resoluciones/res08/74-08.pdf>. Acesso em: 18 nov. 2015.

ARGENTINA. Consejo Federal de Educación (CFE). Resolução no 83, de 30 de julho de 2009. Disponível em: <http://www.me.gov.ar/consejo/resoluciones/res09/83-09.pdf >. Acesso em: 18 nov. 2015.

ARGENTINA. Consejo Federal de Educación (CFE). Resolução no 167, de 28 de março de 2012. Disponível em: <http://www.me.gov.ar/consejo/resoluciones/res12/167-12.pdf>. Acesso em: 18 nov. 2015.

ARGENTINA. Consejo Federal de Educación (CFE). Resolução no 167, de 28 de março de 2012. Anexo I. Plan Nacional de Formación Docente 2012-2015. Disponível em: <http://www.me.gov.ar/consejo/resoluciones/res12/167-12_01.pdf>. Acesso em: 18 nov. 2015.

ARGENTINA. Instituto Nacional de Formación Docente (INFD). 2009. Recomendaciones para la Elaboración de Diseños Curriculares - Profesorado de Educación Artística. Disponível em: $<$ http://cedoc.infd.edu.ar/upload/artistica.pdf >. Acesso em: 18 nov. 2015.

BRASIL. Ministério da Educação. Resolução $n^{\circ} 2$, de $1^{\circ}$ de julho de 2015. Diretrizes Curriculares Nacionais para a formação inicial em nível superior. Disponível em: $<$ http://portal.mec.gov.br/index.php?option=com_docman\&view=download\&alias=17719-res-cne-cp002-03072015\&category_slug=julho-2015-pdf\&Itemid=30192>. Acesso em: 19 nov. 2015.

BRASIL. Ministério da Educação. Resolução no 1, de 16 de janeiro de 2009. Diretrizes curriculares Nacionais dos Cursos de graduação em Artes Visuais. Disponível em: <http://portal.mec.gov.br/cne/arquivos/pdf/2009/rces001 09.pdf>. Acesso em: 19 nov. 2015.

BRASIL. Ministério da Educação. Lei no 9.394, de 20 de dezembro de 1996. Lei de Diretrizes e Bases da Educação Nacional. Disponível em: <http://portal.mec.gov.br/arquivos/pdf/ldb.pdf>. Acesso em: 19 nov. 2015.

BRASIL. Câmara dos Deputados. Projeto de Lei no 7.032. 2010. Disponível em: $<$ http://www.camara.gov.br/proposicoesWeb/fichadetramitacao?idProposicao=470941 >. Acesso em: 19 nov. 2015.

BRASIL. Presidência da República. Lei no 11.769, de 18 de agosto de 2008. Disponível em: <http://www.planalto.gov.br/ccivil_03/_ato2007-2010/2008/lei/111769.htm>. Acesso em: 19 nov. 2015.

BRASIL. Presidência da República. Lei no 11.645, de 10 de março de 2008. Disponível em: <http://www.planalto.gov.br/ccivil 03/ ato2007-2010/2008/lei//11645.htm>. Acesso em 19 nov. 2015.

BRASIL. Presidência da República. Lei no 10.639, de 9 de janeiro de 2003. Disponível em: <http://www.planalto.gov.br/ccivil_03/leis/2003/L10.639.htm>. Acesso em: 19 nov. 2015.

BRASIL. Presidência da República. Lei no 9.394, de 20 de dezembro de 1996. Disponível em: <http://www.planalto.gov.br/ccivil_03/Leis/L9394.htm>. Acesso em: 19 nov. 2015.

BUJAN, F. La construcción de un observatorio latinoamericano de la formación de profesores en las universidades. Educação, Artes e Inclusão. Universidade do Estado de Santa Catarina (UDESC), Florianópolis (Brasil), vol. 8, no 2, dez. 2013. p. 79-99.

BUJAN, F.; FRADE, I.; FONSECA da SILVA, M. C. R. Observatório da formação de professores de artes: uma rede de pesquisa na América Latina. Série Diálogos en Red Nuestra América. v. 1, 2014. p. 135-156.

EVANGELISTA, O. (Org.). O que revelam os slogans na política educacional. 1. ed, v. 1. Araraquara SP: Junqueira e Marin, 2014. $288 \mathrm{p}$.

FONSECA DA SILVA, M. C. R. Formação de professores de arte e perspectivas de atuação política. In: Anais do $3^{\circ}$ Simpósio da Licenciatura em Arte Visuais da FAP e $2^{\circ}$ ENREFAEB Sul. Editora FAP, Curitiba, 2010.

FONSECA DA SILVA, M. C. R.; HILLSHEIM, G. B. D.; PERA, L. P. As políticas governamentais brasileiras e sua influência na formação docente em arte. In: Visibilidades (Lisboa). v. 6, 2014. p. 10-21. 
FRIGOTTO, Gaudêncio. A interdisciplinaridade como necessidade e como problema nas Ciências Sociais. In: Revista do Centro de Educação e Letras da UNIOESTE. v. 10, n. 01, 2008. p. 42-62.

GATTI, B. A.; BARRETTO, E. S. S. Professores do Brasil: impasses e desafios. 1. ed. Brasília: Editora da UNESCO, 2009.

NOSELLA, Paolo. A escola de Gramsci. Porto Alegre: Artes Médicas Sul, 1992.

SAVIANI, Dermeval. Da nova LDB ao novo Plano Nacional de Educação: por uma outra política educacional. Campinas, SP: Autores Associados, 1997.

SAVIANI, Dermeval. A nova lei da educação. Campinas - SP: Autores Associados, 1998.

SAVIANI, Dermeval. Educação em diálogo. 1. ed. Campinas: Autores Associados, v 1, 2011.

SHIROMA, Eneida Oto. Relatório Estadual da Pesquisa Trabalho Docente na Educação Básica no Brasil. Florianópolis, 2010.2 Disponível em: $<$ http://trabalhodocente.net.br/images/publicacoes/84/PESQUISA DOCUMENTAL SANTA CATARIN A.pdf >. Acesso em: 19 nov. 2015.

\section{Maria Cristina da Rosa Fonseca da Silva}

Possui graduação em Educação Artística pela Universidade do Estado de Santa Catarina (1988), mestrado em Educação pela Universidade Federal de Santa Catarina (1998) e doutorado em Engenharia de Produção pela Universidade Federal de Santa Catarina (2004) na linha de mídia e conhecimento. Em 2010 realizou Estágio de Pós-doutorado na Universidad de Sevilla/Espanha desenvolvendo pesquisa junto a Escola da Organización Nacional de Ciegos Espanõles. Em 2011 desenvolveu Estágio de Pós Doutoramento na Universidad Nacional Del Arte - IUNA em Buenos Aires, Argentina . É Coordenadora do Laboratório Interdisciplinar de Formação de Educadores - LIFE da UDESC. Desenvolve programa de Extensão junto ao NUPEART de Assessoria para professores da rede pública de ensino. Atualmente coordena em conjunto com a professora doutora Regina Finck Chambeck o PIBID Interdisciplinar da UDESC.

E-mail: cristinaudesc@gmail.com

Currículo: http://lattes.cnpq.br/5794119392714925

\section{Federico Ignacio Buján}

Doutor em Humanidades e Artes pela Universidad Nacional de Rosario (UNR), Argentina. Realizou estágio pós-doutoral na Escola de Comunicações e Artes da Universidade de São Paulo (ECA-USP). Professor e Pesquisador no Instituto Universitario Nacional del Arte (IUNA). Bolsista Pós-doutoral do Consejo Nacional de Investigaciones Científicas y Técnicas (CONICET), Programa Dispositivos Hipermediales Dinámicos (DHD), Instituto Rosario de Investigaciones en Ciencias de la Educación (IRICE: CONICET-UNR), desenvolvendo pesquisas na área das Tecnologias da Informação e da Comunicação aplicadas a contextos educativos e de pesquisa desde uma perspectiva socio-técnica. Tem experiência nas áreas de Comunicação, Educação, Artes e Semiótica.

E-mail: fbujan@gmail.com

Currículo: http://lattes.cnpq.br/5537662472527832

Recebido em 16 de fevereiro de 2016 Aceito em 30 de março de 2016 